\title{
Electrophysiological dysfunction and cellular disruption of sensory neurones during incubation with Treponema pallidum
}

\author{
S GEORGE OAKES, * LILLIAN A REPESH, $+\mathrm{R} S$ POZOS, * AND \\ T J FITZGERALD‡
}

From the Departments of *Physiology, + Biomedical Anatomy, and $¥$ Medical Microbiology and Immunology, University of Minnesota School of Medicine, Duluth, Minnesota, USA

SUMMARY Treponema pallidum (Nichols strain) was incubated with cultured nerve cells derived from dorsal root ganglia of rat embryos. The electrophysiological response of these neuronal cells was then investigated. Cells exposed to $2 \times 10^{8}$ treponemes $/ \mathrm{ml}$ responded abnormally after 13 hours and failed to respond after 18 hours. In contrast, control preparations exposed to heatinactivated treponemes or to culture medium responded normally after 72 hours. Extended incubation with viable treponemes resulted in various degrees of nerve cell disruption as shown by scanning electron microscopy. With some cells holes in the cytoplasmic membrane were detected; with others a coagulated matrix of apparent nuclear material and remnants of cytoskeletal elements indicated more severe destruction. These findings may explain the painless nature of many of the clinical manifestations of syphilis as well as the severe damage to central nervous system tissue in tertiary and congenital syphilis.

\section{Introduction}

Ovcinnikov and Delektorskij ${ }^{1}$ demonstrated treponemal association with nerve cell tissues within material from syphilitic lesions. Although they did not observe nerve histopathology, they suggested that Treponema pallidum might inactivate nerve function; this in turn could explain the painless nature of most of the clinical manifestations of syphilis. The accompanying paper ${ }^{2}$ described the interaction of $T$ pallidum with cultured cells derived from dorsal root ganglia, superior cervical ganglia, and spinal cord. After six hours' incubation numerous treponemes were attached and the nerve cell morphology was not altered. The purpose of this study was to show that with extended incubation treponemes initially cause electrophysiological dysfunction then morphological disruption of dorsal root ganglia neurones in culture.

Address for-reprints: Dr T J Fitzgerald, Department of Medical Microbiology and Immunology, University of Minnesota School of Medicine, Duluth, Minnesota 55812, USA

Accepted for publication 15 February 1982

\section{Materials and methods}

$T$ PALLIDUM

The Nichols strain was maintained by intratesticular passage. Conditions for extraction have been described. ${ }^{2}$ After slow-speed centrifugation organisms were centrifuged at high speed $(18000 \times g$ for 30 minutes at $4^{\circ} \mathrm{C}$ ) to remove the inflamed testicular constituents. The only departure from previous conditions was the omission of glutathione, cysteine, and dithiothreitol from the treponemal suspending medium. For inactivation by heat treponemes were placed at $56^{\circ} \mathrm{C}$ for 10 minutes.

NERVE TISSUE CULTURE CELLS

Nerve cells were isolated from dorsal root ganglia of 17-19-day-old rat embryos. Cell preparation, medium, and conditions of incubation have been described. ${ }^{2}$ After the cells had grown for 3-4 weeks culture medium was removed and the cells were washed three times with $2 \mathrm{ml}$ treponemal suspending medium. Different concentrations of treponemes were then added in a 2-ml volume. Cells were incubated at $37^{\circ} \mathrm{C}$ in an atmosphere of $92.5 \%$ nitrogen, $5 \%$ carbon dioxide, and $2.5 \%$ oxygen. 
SCANNING ELECTRON MICROSCOPY

The techniques and fixation procedures for examining nerve cells using scanning electron microscopy have been described. ${ }^{2}$

\section{ELECTROPHYSIOLOGICAL METHODS}

Electrical recordings were made directly in the culture dishes on the stage of a Zeiss inverted microscope. The tip of a microelectrode was inserted into a nerve cell. Voltage differences were then measured between this intracellular electrode and a second electrode used as a ground immersed in the extracellular fluid. Electrical pulses were passed through the intracellular electrode and the change in voltage across the cell membranes monitored. Microelectrodes were positioned with a Leitz micromanipulator under direct observation at a magnification of $\times \mathbf{4 0 0}$. The temperature, monitored by a thermistor, was maintained at $37^{\circ} \mathrm{C}$ with an overhead heat lamp. Recordings were made in tissue culture medium to avoid disturbances in the infective process and to promote cell survival over an extended period of time.

Fine-tipped glass microelectrodes were filled with $4 \mathrm{~mol} / 1$ potassium acetate $(\mathrm{pH} 7 \cdot 0)$ with resistances of $30-80 \mathrm{~m} \Omega$. A bridge circuit (Mentor N-950, Minneapolis, Minnesota) was used for simultaneous current stimulation and voltage recordings. The cells were stimulated with a depolarising pulse, and the action potentials were monitored on an oscilloscope and recorded on a Hewlett-Packard FM tape recorder. The electrophysiological responses were analysed with a computer programme written for a PDP-12 computer (unpublished data). Values for the different experimental conditions were compared using a standard statistical package.

\section{Results}

Neuronal cells were presumptively identified in the previous study ${ }^{2}$ by their characteristic morphology. Definitive identification is based on the ability of these cells to respond to electrical stimulation with an action potential. Fig la shows a typical action potential and defines the indices of resting membrane potential, spike amplitude, maximum rate of rise, and after-hyperpolarisation maximum. Normal action potentials are readily distinguished from abnormal action potentials.

Attempts were made to evaluate the influences of $T$ pallidum on the genesis and character of the action potential of cultured nerve cells. In preliminary experiments control preparations failed to respond appropriately. Analysis of different components of the culture medium showed that glutathione, cysteine, and dithiothreitol prevented typical responses. These three reducing agents were then omitted from the treponemal suspending medium. Various concentrations of treponemes were added to the cultured cells. Controls included culture medium alone or heat-inactivated treponemes. At different times after inoculation neuronal cells were electrically stimulated and the action potentials measured. In the first two experiments the two control preparations showed normal responses after incubation for 72 hours. In contrast, neuronal cells exposed to $2 \times$ $10^{8}$ treponemes $/ \mathrm{ml}$ lost their ability to respond after eight hours in one experiment and after 10 hours in the second.

The results of a third experiment are shown in table I. Normal responses were defined as those that fell within $\pm 1 \mathrm{SD}$ of the resting membrane potential and spike amplitude for the controls not containing
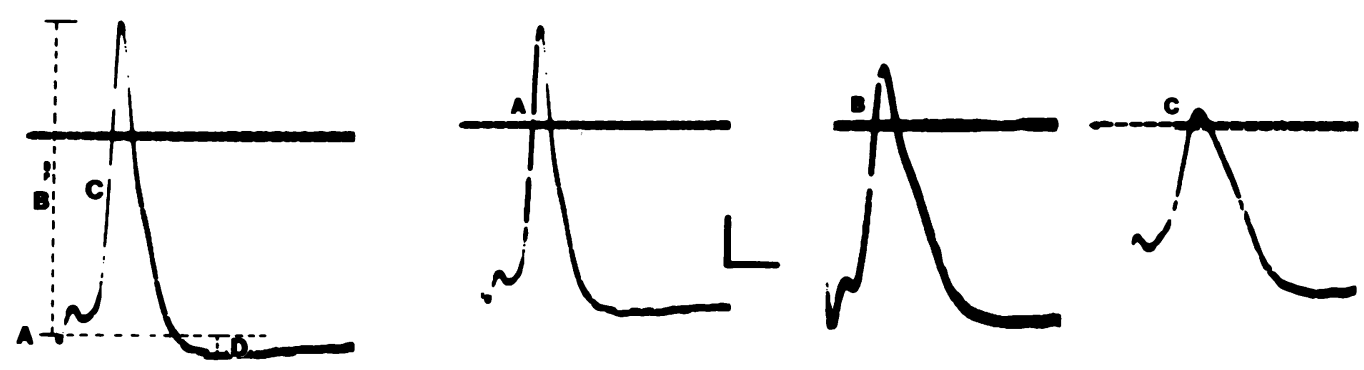

a

b.

FIG 1(a) A typical action potential of a dorsal root ganglion neurone. Electrophysiological indices are defined: $A$, resting membrane potential $(\mathrm{mV}) ; B$, spike amplitude $(\mathrm{mV}) ; C$, maximum rate of rise ( $\mathrm{mV} / \mathrm{ms}) ; \mathrm{D}$, afterhyperpolarisation maximum $(\mathrm{mV})$. (b) Electrophysiological responses of neuronal cells exposed to culture medium or treponemes (A, normal control; $B$ and $C$, abnormal treponemal-impaired). The calibration scale is $20 \mathrm{mV}$ along the $y$ axis and $1 \mathrm{~ms}$ along the $x$ axis. 
TABLE I Treponemal inter,erence with electrophysiological responses of cultured dorsal root ganglia

\begin{tabular}{|c|c|c|c|}
\hline \multirow[b]{2}{*}{ Time (hours) } & \multicolumn{3}{|c|}{ Normal response $* /$ total tested } \\
\hline & $\begin{array}{l}\text { Without } \\
\text { treponemes }\end{array}$ & $\begin{array}{l}2 \times 10^{8} \\
\text { Treponemes } / \mathrm{ml}\end{array}$ & $\begin{array}{l}1 \times 10^{8} \\
\text { Treponemes } / \mathrm{ml}\end{array}$ \\
\hline $\begin{array}{r}0 \\
5 \\
7 \\
10 \\
13 \\
18 \\
26\end{array}$ & $10 / 10$ & $\begin{array}{l}5 / 5 \\
5 / 5 \\
5 / 5 \\
5 / 5 \\
3 / 11 \\
0 / 5 \\
0 / 5\end{array}$ & $\begin{array}{c}5 / 5 \\
6 / 6 \\
10 / 12\end{array}$ \\
\hline
\end{tabular}

* Defined as those that fall within \pm 1 SD of the resting membrane potential and spike amplitude for the controls not containing treponemes.

treponemes. At 0 hours the nerve cells exposed to control medium and to the two different concentrations of $\boldsymbol{T}$ pallidum functioned normally. After incubation for 26 hours, 10 of 10 cells in the control preparation responded normally. With treponemes at $2 \times 10^{8}$ organisms/ml abnormal responses were detected after 13 hours; only three of 11 cells responded normally. After 18 hours action potentials could not be elicited. With treponemes at $1 \times 10^{8}$ organisms/ml normal responses were detected in five of five cells after 18 hours and in 10 of 12 cells after 26 hours.

Fig $1 \mathrm{~b}$ shows representative action potentials of control cells (A) and test cells (B and C) incubated with treponemes for 13 hours. The mean values determined by combining the indices for individual nerve action potentials in each experimental condition are shown in table II. For control preparations not exposed to $T$ pallidum no significant differences were apparent after 0 and 26 hours; these two sets of values were combined. Incubation for 13 hours with $2 \times 10^{8}$ organisms $/ \mathrm{ml}$ resulted in abnormal electrophysiology in eight of 11 neuronal cells. Comparison of the individual indices for these cells showed significant differences in resting membrane potential, spike amplitude, maximum rate of rise, and after- $\mathbb{D}$ hyperpolarisation maximum compared with the controls. At this time the morphology of the neuronal cells was unchanged.

In further experiments nerve cultured cells were $\stackrel{5}{+}$ inoculated with 1 to $2 \times 10^{8}$ organisms $/ \mathrm{ml}$ and controls of culture medium, heated treponemes, and $\frac{\bar{D}}{\bar{D}}$ the high-speed supernatant. Cultures were examined $\vec{\sigma}$ with phase-contrast microscopy. After incubation 2 for 24 hours pronounced damage to both neuronal $\%$ cells and fibroblastic cells was apparent in cultures $\vec{\circ}$ exposed to viable treponemes. Neuronal morphology was not altered in the control preparations incubated $\vec{\omega}$ for 24 hours.

Degradation was related to the concentration of $T \stackrel{0}{=}$

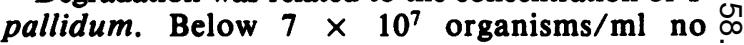
morphological or electrophysiological changes were observed after 48 hours' incubation. After 48 hours, N motility of the organisms was sharply decreased probably because of the omission of reducing agents from the culture medium.

Treponemal degradation of neuronal cells was evident by scanning electron microscopy. Cultures were inoculated with $2 \times 10^{8}$ organisms $/ \mathrm{ml}$. Figure 2 shows atypical morphology of a nerve cell after $16 \ddot{\bullet}$

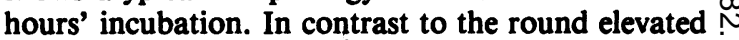
appearance of normal neurones the cells assumed a flattened morphology, and their surfaces were marked with irregular holes. Some cells were more damaged than others.

Various stages of treponemal-mediated nerve-cell $\stackrel{\circ}{\varnothing}$ degradation are shown in figs 3-5. Fig 3 shows the ghost-like remnant of an apparent dorsal root ganglia cell. The morphology was greatly altered. The nuclear profile in the centre of the cell deteriorated to a coagulated matrix. Remnants of cellular substratum attachment processes can be seen peripherally. At higher magnification of this peripheral area (fig 4) the edge of the cell is demarcated by fibrous extensions, which are associated with small bleb-like particles. These may

TABLE II Selected indices of electrical properties of cultured dorsal root ganglia infected with treponemes

\begin{tabular}{|c|c|c|c|c|c|}
\hline \multirow[b]{2}{*}{ Preparation* } & \multirow[b]{2}{*}{$\begin{array}{l}\text { Incubation } \\
\text { time (hours) }\end{array}$} & \multicolumn{4}{|c|}{ Electrical properties (mean $\pm S E M$ ) } \\
\hline & & $\begin{array}{l}\text { Resting membrane } \\
\text { potential }(\mathrm{mV})\end{array}$ & $\begin{array}{l}\text { Spike amplitude } \\
(\mathrm{mV})\end{array}$ & $\begin{array}{l}\text { Maximum rate of } \\
\text { rise }(\mathrm{mV} / \mathrm{ms})\end{array}$ & $\begin{array}{l}\text { After-hyperpolarisation } \\
\text { maximum }(m V)\end{array}$ \\
\hline $\begin{array}{l}\text { Without treponemes (15) } \\
\text { With } 2 \times 108 \text { treponemes/ml (4) } \\
\text { With } 1 \times 108 \text { treponemes } / \mathrm{ml} \text { (5) } \\
\\
\text { (6) } \\
\text { (9) }\end{array}$ & $\begin{array}{r}26 \\
7 \\
10 \\
13 \\
13 \\
18 \\
26\end{array}$ & $\begin{array}{l}-55 \cdot 61 \pm 3 \cdot 85 \\
-54 \cdot 17 \pm 2 \cdot 40 \\
-54 \cdot 31 \pm 1 \cdot 25 \\
-50 \cdot 12 \pm 3 \cdot 86 t \\
-56 \cdot 43 \pm 3 \cdot 45 \\
-54 \cdot 77 \pm 4 \cdot 50 \\
-50 \cdot 63 \pm 4 \cdot 29 t\end{array}$ & $\begin{array}{l}81 \cdot 65 \pm 9 \cdot 13 \\
89 \cdot 18 \pm 3 \cdot 39 t \\
83 \cdot 79 \pm 5 \cdot 56 \\
65 \cdot 66 \pm 16 \cdot 11 t \\
77 \cdot 11 \pm 8 \cdot 84 \\
80 \cdot 51 \pm 14 \cdot 96 \\
73 \cdot 36 \pm 14 \cdot 16\end{array}$ & $\begin{array}{l}204 \cdot 11 \pm 40 \cdot 41 \\
220 \cdot 60 \pm 9 \cdot 25 \\
212 \cdot 34 \pm 26 \cdot 2 \\
146 \cdot 64 \pm 61 \cdot 96+ \\
195 \cdot 40 \pm 38 \cdot 73 \\
197 \cdot 34 \pm 63 \cdot 51 \\
170 \cdot 52 \pm 60 \cdot 55\end{array}$ & $\begin{array}{l}-6 \cdot 40 \pm 1: 48 \\
-3 \cdot 65 \pm 1 \cdot 02 t \\
-4 \cdot 42 \pm 1 \cdot 18 t \\
-2 \cdot 81 \pm 0 \cdot 9 t \\
-4 \cdot 06 \pm 2 \cdot 11 \\
-6 \cdot 05 \pm 2 \cdot 02 \\
-5 \cdot 8 \pm 1 \cdot 73\end{array}$ \\
\hline
\end{tabular}

SEM $=$ Standard error of mean

* No of neuronal cells tested given in parentheses

tStatistically significant, $\mathrm{P}<0 \cdot 05$ 


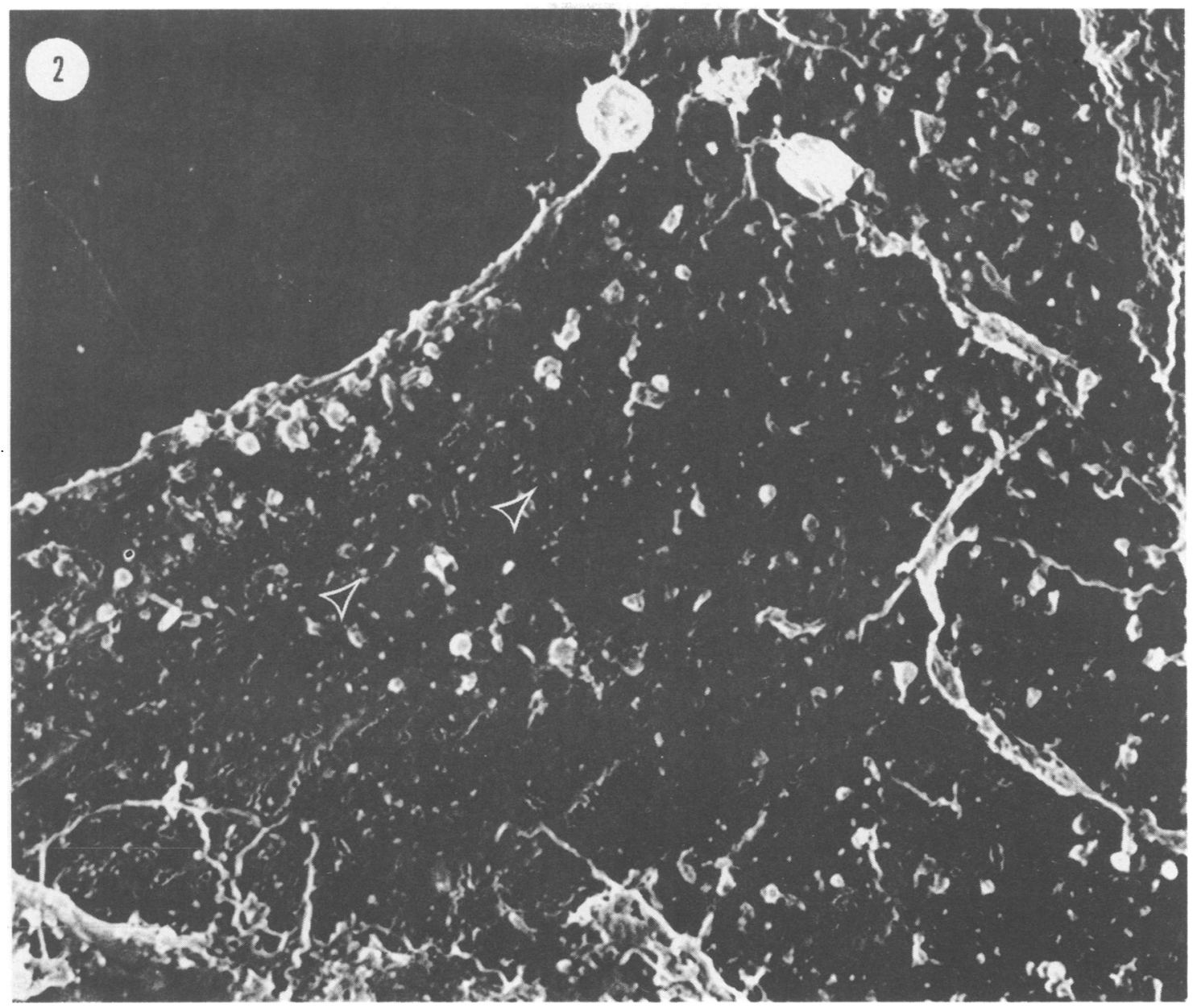

FIG 2 Scanning electron micrograph of a nerve cell derived from dorsal root ganglia incubated for 16 hours with $T$ pallidum. The flattened cell shows irregular holes (arrowheads) on its surface. ( $\times 3900)$.

represent the cytoskeletal cores of radially extending retraction fibrils.

Further degradation of a nerve cell is shown in fig 5. The cytoplasm is difficult to differentiate from the condensed nucleus. The cell periphery is profiled by small blebs, and the fibrous extensions of the cellular margin have apparently been degraded.

\section{Discussion}

A number of reports have shown that cultured nerve cells accurately reflect in-vivo phenomenon..$^{5-8}$ These cultured cells elaborate neuritic processes; they respond to voltage stimulation with typical action potentials similar to those generated in vivo; they form functional contacts with one another, and action potentials are transmitted to neighbouring neuronal cells. In addition, different types of nerve tissues that vary in structure and function show the same variations after in-vitro cultivation. Thus, the observations in this paper should be representative of in-vivo phenomenon.

The accompanying study ${ }^{2}$ showed that $T$ pallidum attached to cultured cells derived from dorsal root ganglia, superior cervical ganglia, and spinal cord. This study extends these findings to longer periods of incubation and demonstrates treponemal dysfunction and morphological damage to neuronal cells of dorsal root ganglia. This detrimental effect was dependent on attachment of treponemes. Heatinactivated organisms failed to attach, and correspondingly nerve cell function and morphology were 


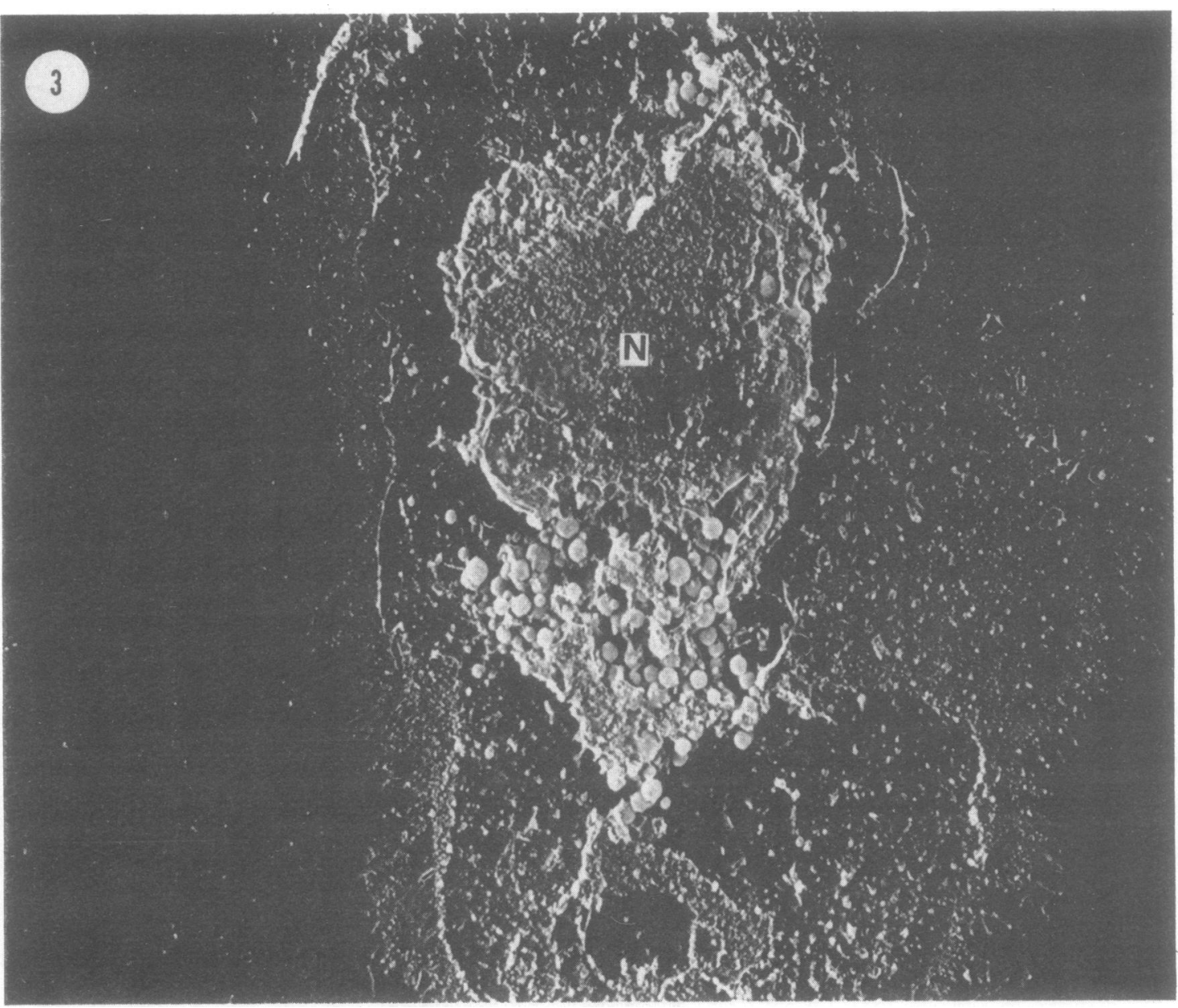

FIG $3 A$ dorsal root ganglion cell degraded by extended incubation with $T$ pallidum. The nuclear $(N)$ profile is readily apparent. The cytoplasmic remnants are represented by an irregular fibrous meshwork and large spheres of various sizes. $(\times 1300)$.

unchanged. Concentrations below $7 \times 10^{7}$ organisms $/ \mathrm{ml}$ did not adversely influence nerve cell function or morphology. Damage at this, or lower concentrations, may have resulted if treponemal survival was extended. Without reducing agents, however, organisms retained motility in our system for about 48 hours. Most importantly, the concentrations that were detrimental $\left(2 \times 10^{8}\right.$ treponemes $/ \mathrm{ml}$ ) are consistent with syphilitic infection. The critical number of organisms required for the initial manifestations of erythema and induration is approximately $10^{7}$ treponemes. $^{9}$ Assuming a generation time of 30 hours, within 4-5 days and before ulceration occurs, over $10^{8}$ treponemes should be present. Neuronal cells lost their ability to respond electrophysiologically (8-10 hours) before morpho- logical changes became apparent (16 hours). This is the first report of in-vitro nerve dysfunction and disruption attributed to the attachment of bacteria. A normal action potential requires an intact neuronal membrane. Thus, the first detectable damage must $\tilde{O}$ have reflected alterations in nerve cell membranes. With further incubation morphological damage $N$ occurred as manifested by holes in the nerve cell $\omega$ membrane and a flattening of the typical raised 2 morphology. Further disruption of nerve cell 1 integrity was characterised by condensation of the nucleus and an outlining of the cellular boundaries by fibrous cytoskeletal remnants. Similar morphological alterations have been shown in cells treated with Triton-X, a detergent that solubilises the plasma membrane, ${ }^{10}{ }^{11}$ or EGTA, a $\mathrm{Ca}^{++}$specific chelator. 


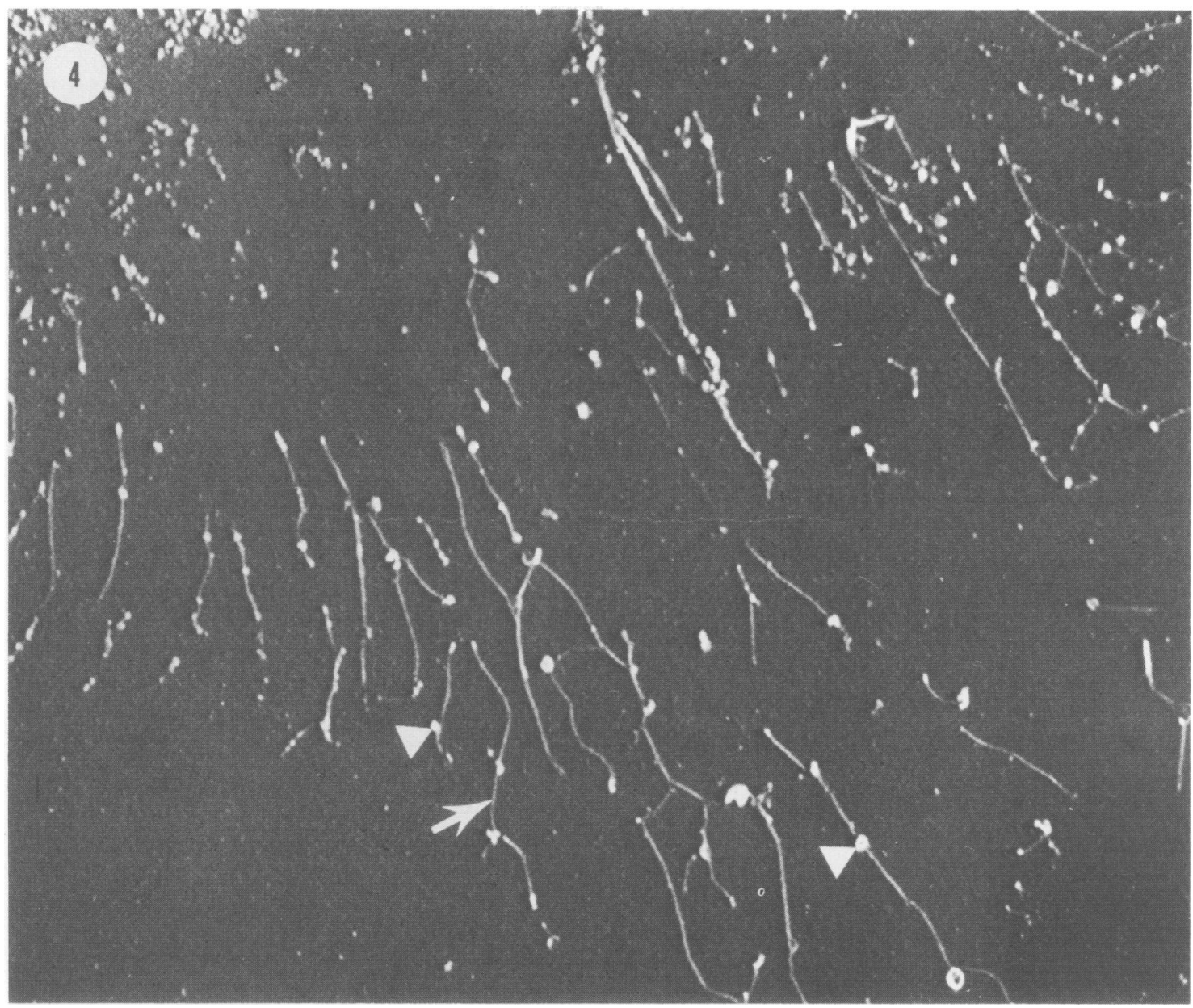

FIG 4 A higher magnification of the cellular periphery of the nerve cell in fig 3. Note the cytoskeletal cores of retraction fibres (arrow) associated with bleb-like particles (arrowheads). ( $\times 3400)$.

These processes can be easily broken by gentle manipulation and separated from material that remains attached to the substratum. This substrate-attached material mediates cell adhesion and is primarily composed of fibronectin, glycosaminoglycans, and cytoskeletal proteins. ${ }^{12}$ These areas of the cultured cells are apparently somewhat more resistant to degradation by $T$ pallidum.

Oakes et $a l^{13}$ recently reported similar detrimental influences of herpes viruses on dorsal root ganglia in culture. After viral inoculation alterations in electrophysiological indices were observed within four hours. Morphological alterations were detected after 16 hours; at this time less than half the neuronal cells responded with action potentials. Nerve cells were totally 'destroyed after 48 hours' incubation. The authors suggested that herpes virus reduced the sodium ion conductance of neuronal cells.

The findings in this study may partially explain two unknown factors of syphilitic infection: (a) the painless nature of most of the clinical manifestations of each stage of infection and (b) the severe nerve degeneration in tertiary and congenital syphilis. Two preliminary reports have shown that treponemes are associated with nerve fibres within lesion material. ${ }^{1} 14$ In our tissue culture system after treponemal attachment to neuronal cells the initial effect was a functional impairment of the ability of these cells to generate an action potential. With further incubation morphological disruption of the neuronal cells was observed. Clinical manifestations of primary and secondary infection are usually evident for 2-6 weeks, 


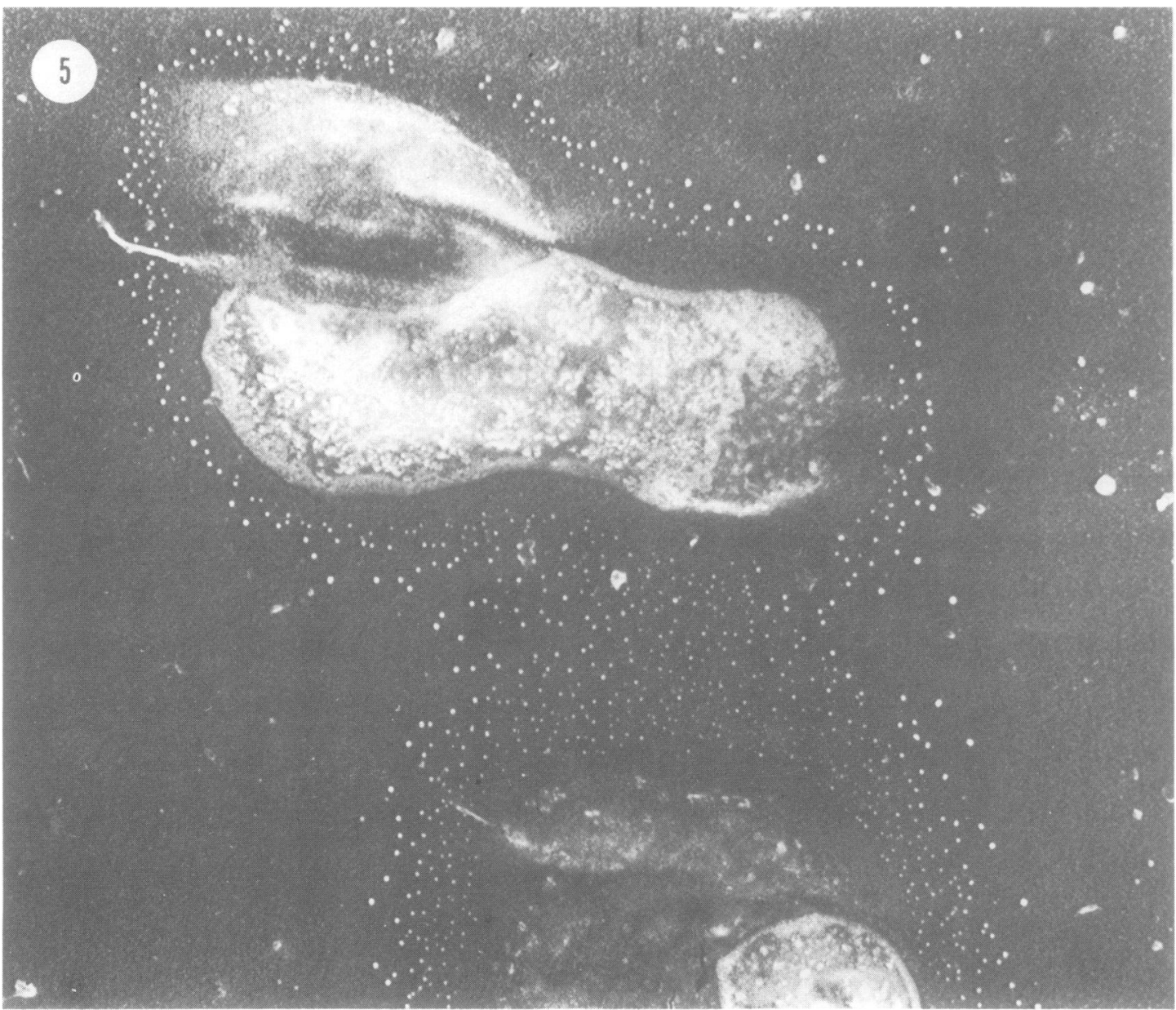

FIG 5 Nerve cell incubated for 16 hours with $T$ pallidum showing greatly altered morphology. The nuclear and cytoplasmic constituents are difficult to distinguish. The outline of the cell is marked by small cytoplasmic particles, probably remnants of attachment contacts. $(\times 1400)$.

whereas manifestations of tertiary syphilis may last for years. In primary and secondary stages nerve deficits do not occur. The presence of treponemes within tissues for shorter periods of time (weeks) may interfere transiently with nerve function and account for the lack of pain. After healing pain receptors would return to normal without nerve deficits. In tertiary and congenital syphilis nerve damage frequently occurs. The presence of treponemes within tissues for longer periods (years) may result in morphological destruction causing damage to the central nervous system, particularly the cerebral cortex, spinal cord, and peripheral nerves.

We wish to acknowledge the excellent technical assistance of Paul Lima for tissue culture prepar- ations, Eileen Gannon for treponemal preparations, and Anne Utyro for developing and processing the photomicrographs. This research was supported by the Public Health Service and National Institute of Allergy and Infectious Diseases grant AI 16-585, the National Institute of Neurological and Communicative Disorders and Stroke grant NS-1-325, and the Minnesota Medical Foundation grant 0762-5836.

\section{References}

1. Ovcinnikov NMJ, Delektorskij VV. Treponema pallidum in nerve fibres. $B r J$ Vener Dis 1974;51:10-8.

2. Repesh LA, Fitzgerald TJ, Oakes SG, Pozos RS. Scanning electron microscopy of the attachment of Treponema pallidum to nerve cells in vitro. Br J Vener Dis 1982;58:211-9. 
4. Fitzgerald TJ, Johnson RC, Miller JN, Sykes JA. Characterization of the attachment of Treponema pallidum (Nichols strain) to cultured mammalian cells and the potential relationship of attachment to pathogenicity. Infect Immun 1977; 18: $467-78$.

5. Crain SM. Neurophysiologic studies in tissue culture. New York: Raven Press, 1976.

6. Fishbach GD, Nelson PG. Cell culture in neurobiology. In: Kandal F, ed. Handbook of physiology - the nervous system I. Bethesda, Maryland: American Physiology Society, 1977: $719-74$.

7. Minna J, Nelson P, Peacock J, Glazer D, Nirenberg M. Genes for neuronal properties expressed in neuroblastoma $X \mathrm{~L}$ cell hybrids. Proc Nat Acad Sci 1971;68:234-9.

8. O'Lague PH, Potter DD, Furshpan EJ. Studies on rat sympathetic neurons developing in cell culture. I Growth characteristics and electrophysiological properties. Dev Biol 1978; 67:384-403.
9. Turner TB, Hollander DH. Biology of the treponematoses. WHO Monogr Ser No 35, 1957.

10. Bell PB, Miller MM, Carraway KL, Revel JP. SEM-revealed changes in the distribution of the triton insoluble cytoskeleton of Chinese hamster ovarian cells induced by dibutyrl cyclic AMP. In: Becker RP, Johari O, ed. Scanning electron microscopy, vol 2. O'Hare, Illinois: SEM Inc AMF, 1978: 899-906.

11. Gospodarowicz D, Delgado D, Vlodvasky I. Permissive effect of the extracellular matrix on cell proliferation in vitro. Proc Nat Acad Sci 1980; 77:4094-8.

12. Culp LA, Murray BA, Rollins BJ. Fibronectin and proteoglycans as determinants of cell-substrate adhesion. $J$ Supramol Struct 1979; 11:401-27.

13. Oakes SG, Petry RW, Ziegler RJ, Pozos RS. Electrophysiological changes of HSV-1 infected dorsal root ganglia neurons in culture. J Exp Neurol Neuropathol 1981; 40:380-9.

14. Gregoriew PS. Uchebnik venericheskich i kojnich beleznej. Biomedgiz 1938; NKA USSR. 